\section{FRI0261 SKIN CANCER IN A COHORT OF SYSTEMIC LUPUS ERYTHEMATOSUS}

M. Taraborelli ${ }^{1}$, C. Genitori ${ }^{2}$, I. Cavazzana ${ }^{3}$, M. Fredi ${ }^{3}$, A. Tincani ${ }^{4}$ P. Calzavara Pinton ${ }^{2}$, F. Franceschini ${ }^{3} .{ }^{1}$ Internal Medicine Unit, Mellino Mellini Hospital, Chiari (Brescia); ${ }^{2}$ Dermatology Unit and Chair, University and Spedali Civili of Brescia; ${ }^{3}$ Rheumatology Unit, Spedali Civili of Brescia; ${ }^{4}$ Rheumatology Unit and Chair, University and Spedali Civili of Brescia, Brescia, Italy

Background: Conflicting results about the prevalence of skin cancer in Systemic Lupus Erythematosus (SLE) have been reported in the literature $[1,2]$.

Objectives: The aim of this study was to retrospectively evaluate the prevalence of malignancies, with a particular focus on skin cancers, in a cohort of SLE patients followed in a single Center.

Methods: All the SLE patients classified according to the ACR and SLICC criteria, attending the Rheumatology and Clinical Immunology Unit of Spedali Civili, Brescia, were retrospectively evaluated. Clinical and laboratory data were obtained from clinical charts. Diagnoses of skin cancers (melanoma and nonmelanoma: basalioma, squamous cell carcinoma) and other malignancies were recorded together with the time elapsed from diagnosis of SLE. Univariate analysis was performed to compare characteristics of patients with $\left(\mathrm{K}_{+}\right)$and without (K-) cancer. We also compared the prevalence of cancer in our population to that reported in the italian general population (from the Italian National Institute of Statistics, ISTAT, report 2014).

Results: In a cohort of 511 SLE patients (92\% females, $95 \%$ caucasian) regularly followed from 1972 to 2016 (mean age at diagnosis 31 years \pm 13 and median follow-up 12 years, range 1-40) we detected 51 cases (9,9\%) with a history of malignancy: melanoma was reported in $3(0.5 \%)$, non melanoma skin cancer (NMSC) in $11(2 \%)$ and other malignancies in 38 cases $(7.4 \%)$. Table I reports the comparison between patients with and without cancer. Patients with cancer, as well as cases with NMSC and non cutaneous malignancies, showed a higher age at disease onset $(p<0.0001 ; p=0.002$ and $p<0.0001$ respectively) and higher SLE damage $(p<0.0001 ; p=0.019$ and $p<0.0001$ respectively) compared with patients without malignancies. Patients with melanoma showed the same age at SLE onset, but a higher prevalence of discoid lupus $(p<0.0001)$ and oral ulcer history $(\mathrm{p}=0.02)$. No difference in serological SLE features or in disease activity were detected between groups. The prevalence of melanoma in our cohort $(0.5 \%)$ was only slightly higher than the one reported in the northern Italian general population $(0.2 \%)$, while the prevalence of NMSC $(2 \%)$ resulted to be significantly higher than that reported in the same population (prevalence of spinocellular and basocellular cancer $0.1 \%$ and $0.5 \%$ respectively).

\begin{tabular}{|c|c|c|c|c|c|c|}
\hline Variable & $\begin{array}{c}\text { All } \\
\text { n.5ll }\end{array}$ & $\begin{array}{c}\text { K+ } \\
\text { n. 51 }\end{array}$ & $\begin{array}{c}\text { K- } \\
\text { n. } 460\end{array}$ & \begin{tabular}{|c|} 
melan oma \\
n.3
\end{tabular} & $\begin{array}{c}\text { NMSC } \\
\text { n. } 11\end{array}$ & $\begin{array}{c}\text { Other } \\
\text { tumors } \\
\text { n. } 38\end{array}$ \\
\hline Male sex, $\mathrm{n}(\%)$ & $40(8)$ & $1(1.9)$ & $39(8.4)$ & $O(0)$ & 0 & $1(2.6)$ \\
\hline $\begin{array}{l}\text { Mean age at diagnosis (years), } \\
\text { (SD) }\end{array}$ & $31.4(12.7)$ & $41(14.48)$ & $32(12.1)$ & $21(1.5)$ & $43(18)$ & $43(12.6)$ \\
\hline $\begin{array}{l}\text { Mean disease duration years } \\
\text { (SD) }\end{array}$ & $16.31(9.53)$ & $18(22)$ & $16(9.3)$ & $20(4.5)$ & $15(11.7)$ & $18(11.3)$ \\
\hline $\begin{array}{l}\text { Mean SLEDAI-2K at inclusion } \\
\text { (SD) }\end{array}$ & $11.6(6.02)$ & $12.18(5.81)$ & $11.6(6)$ & $17.33(\$ .96)$ & $10.3(2)$ & $12.2(6)$ \\
\hline Mean last SLICC (SD) & $1.5(1.6)$ & $\hat{3}(1.85)$ & $1(1.5)$ & $3.67(2.8)$ & $2(1.5)$ & $3(1.55)$ \\
\hline Discoid lupus (\%) & 32 & $3(5.8)$ & $29(6.3)$ & $3(100)$ & $0(0)$ & $3(7.8)$ \\
\hline Acute cutaneous lupus (\%) & $270(53)$ & $24(47)$ & $246(53.4)$ & $3(100)$ & $5(45.4)$ & $17(44.7)$ \\
\hline Photosensitivity $(\%)$ & $246 / 502(49)$ & $21(41.1)$ & $225(48.9)$ & $1(33.3)$ & $5(45.4)$ & $16(42.1)$ \\
\hline Glomerulonephritis $(\%)$ & $160(31)$ & $13(25.4)$ & $147(31.9)$ & $1(33.3)$ & $2(18.1)$ & $10(26.3)$ \\
\hline Arthritis (\%) & $298(58)$ & $34(66.6)$ & $264(57.3)$ & $3(100)$ & $9(81.8)$ & $23(60.5)$ \\
\hline Oral ulcers $(\%)$ & $170(33)$ & $12(23.5)$ & $158(34.3)$ & $3(100)$ & $0(0)$ & $9(23.6)$ \\
\hline Chronic alopecia (\%) & $47(9,2)$ & $5(9.8)$ & $39(8.4)$ & $1(33.3)$ & $1(9)$ & $3(7.8)$ \\
\hline Peurisy (\%) & $81(10)$ & $10(19.6)$ & $71(15.4)$ & $0(0)$ & $4(36.3)$ & $6(15.7)$ \\
\hline Pericarditis (\%) & $63(12)$ & $5(9.8)$ & $58(12.0)$ & $0(0)$ & $2(18.1)$ & $3(7.8)$ \\
\hline Leucopenia $(\%)$ & $134(26)$ & $14(27.4)$ & $120(26)$ & $3(100)$ & $5(45.4)$ & $7(18.4)$ \\
\hline Lymphopenia $(\%)$ & $73(14)$ & $?(13.7)$ & $66(14.3)$ & $1(33.3)$ & $2(18.1)$ & $5(13.1)$ \\
\hline Thrombocytopenia (\%) & $91(18)$ & $9(17.6)$ & $82(17.8)$ & $1(33.3)$ & $1(9)$ & $7(18.4)$ \\
\hline $\begin{array}{l}\text { Deep vein thrombosis/ } \\
\text { pulmonary embolism (\%) }\end{array}$ & $43(8.4)$ & $4(7.8)$ & $37(8)$ & $0(0)$ & $1(9)$ & $4(10.5)$ \\
\hline Anti-dsDNA $(\%)$ & $439(86)$ & $43(84.3)$ & $396(86)$ & $3(100)$ & $10(90.9)$ & $31(81.5)$ \\
\hline Anti-ENA $(\%)$ & $297(38)$ & $27(52.9)$ & $270(58.0)$ & $2(65.6)$ & $5(45.4)$ & $20(52.6)$ \\
\hline Antiphospholipid syndrome (\%) & $70 / 509(13.7)$ & $8(15.6)$ & $62(13.4)$ & $0(0)$ & $2(18.1)$ & $6(15.7)$ \\
\hline Lupus anticoagulant & $115 / 326(35.3)$ & $14(27.4)$ & $136(29.5)$ & $1(33.3)$ & $3(27.2)$ & $10(26.3)$ \\
\hline $\mathrm{aCL}(\mathrm{IgG}$ and or $\mathrm{Ig} \mathrm{M})$ & $186 / 458(40.6)$ & $26(50.9)$ & $204(44.3)$ & $0(0)$ & $6(54.5)$ & $19(50)$ \\
\hline anti-B2GPI $(\mathrm{Ig} G$ and $\mathrm{cr}$ I & on & $25(49)$ & s. & $2(65.6)$ & $3(27.2)$ & $20(52.6)$ \\
\hline
\end{tabular}

Conclusions: Non-melanoma was the most common skin cancer observed in our SLE cohort. Its prevalence appeared to be higher than that reported in the general poopulation. SLE patients with melanoma showed a higher frequency of cutaneous lupus history compared with other SLE patients.

References:

[1] Cao L et al PLoS One 2015;10:1-21.

[2] Goobie GC et al. Current Opinion Rheumatology 2015;27:454-60.

Disclosure of Interest: None declared

DOI: 10.1136/annrheumdis-2017-eular.4627

\section{FRI0262 CLINICAL, LABORATORY AND IMMUNOLOGICAL CHARACTERISTICS OF 413 PATIENTS WITH SYSTEMIC LUPUS ERYTHEMATOSUS IN SOUTH KOREA: A MULTICENTER} RETROSPECTIVE COHORT STUDY

E.-K. Park ${ }^{1}$, S.-G. Lee ${ }^{1}$, J.-H. Park ${ }^{1}$, S.-M. Kweon ${ }^{1}$, D.H. Sohn ${ }^{2}$, Y. Kim ${ }^{3}$,
G.-T. Kim ${ }^{3}$, Y.-S. Suh ${ }^{4}$, H.-O. Kim ${ }^{4}$, J.-W. Lee ${ }^{5} .{ }^{1}$ Internal Medicine, Pusan National University School of Medicine, Pusan National University Hospital, Busan; ${ }^{2}$ Microbiology and Immunology, Pusan National University School of Medicine, Yangsan; ${ }^{3}$ Internal Medicine, Kosin University College of Medicine, Busan; ${ }^{4}$ Internal Medicine, Gyeongsang National University School of Medicine, Gyeongsang National University Changwon Hospital, Changwon; ${ }^{5}$ Internal Medicine, Busan St. Mary's Hospital, Busan, Korea, Republic Of

Background: Epidemiologic studies have described clinical characteristics of patients with systemic lupus erythematosus (SLE) in Middle Eastern Asia and Western countries and marked ethnic and geographic differences in the prevalence, severity and outcome of SLE have been reported. However, data from Northeast Asia countries including South Korea are lacking.

Objectives: To investigate demographic, clinical, laboratory and immunological characteristics and prognosis of patients with SLE in South Korea.

Methods: We retrospectively evaluated 413 SLE patients (380 female, 33 male, mean age 40.6 years) diagnosed at 3 tertiary rheumatology centers in South Korea from 1992 to 2016 by reviewing medical chart. All patients fulfilled 1997 revised American College of Rheumatology classification criteria for SLE and were ethnically Korean.

Results: The mean $( \pm S D)$ age at disease diagnosis was $30.9( \pm 12.8)$ years and the median (IQR) disease duration was $108(60-168)$ months. The commonest clinical manifestations in our patients were arthritis $(59.1 \%)$, fever $(49.9 \%)$, malar rash $(48.4 \%)$, alopecia $(43.8 \%)$ and oral ulcer $(35.1 \%)$. The frequency of major organ involvement was as follows: biopsy-proven lupus nephritis $(40.7 \%)$, neuropsychiatric involvement (19.4\%), secondary anti-phospholipid antibody syndrome $(6.1 \%)$ and lupus pneumonitis $(1.7 \%)$. Class IV $(41.1 \%)$ was the most common type of lupus nephritis followed by class $V(15.5 \%)$. Regarding hematologic abnormalities, the cumulative incidence of leucopenia was $74.3 \%$, thrombocytopenia $46.5 \%$, lymphopenia $45.1 \%$ and hemolytic anemia $8.7 \%$. Antinuclear antibodies were detected in $97.8 \%$, anti-Sm in $38.4 \%$, anti-dsDNA IgG in $56.5 \%$, anti-cardiolipine IgG in $27.4 \%$, anti-cardiolipine IgM $11.8 \%$, lupus anticoagulant in $23.2 \%$, anti-Ro in $62.3 \%$, anti-La $30.2 \%$ and anti-RNP in $47.9 \%$. Twenty (4.8\%) patients died during median follow-up of 84 months and the 5 -year and 10 -year survival rates were $96.9 \%$ and $95.5 \%$, respectively (Figure 1). The major causes of death were infection $(35 \%)$ and diffuse alveolar hemorrhage $(20 \%)$. In multivariable Cor regression models, male ( $H R=8.68, p<0.001)$, age at diagnosis $\leq 16$ years $(H R=3.33, p=0.033)$, serositis $(H R=3.04, p=0.018)$ and thrombocytopenia $(H R=3.23, p=0.041)$ were associated with poor survival, while SLE patients with hydroxychloroquine use showed better survival $(H R=0.11$, $\mathrm{p}=0.001$ ).

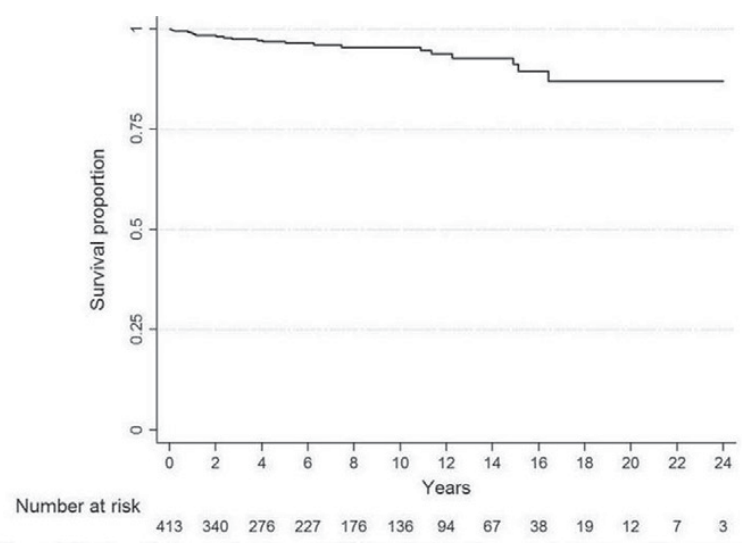

Figure 1. Kaplan-Meier survival curve of 413 patients with systemic lupus erythematosus

Conclusions: Compared with data from other countries, the higher prevalence of hematologic manifestatons and positive anti-Ro antibody were prominent feature of South Korean SLE patients. Overall survival rate in our patients was better than that in other populations.

References:

[1] Khanfir MS et al. TULUP (TUnisian LUPus): a multicentric study of systemic lupus erythematosus in Tunisia. Int J Rheum Dis 2013;16:539-46.

[2] Al Arfaj AS et al. Clinical and immunological manifestations in 624 SLE patients in Saudi Arabia. Lupus 2009;18:465-73.

Disclosure of Interest: None declared

DOI: 10.1136/annrheumdis-2017-eular.2284

\section{FRI0263 SYSTEMIC DISEASE ACTIVITY PROGRESSION IN A LARGE COHORT OF PRIMARY SJÖGREN'S SYNDROME: A LONG-TERM FOLLOW-UP DATA BASED ON THE ESSDAI SCORE}

L. Quartuccio, S. Zandonella Callegher, S. Gandolfo, C. Fabro, S. De Vita. Rheumatology Clinic, Udine Hospital Santa Maria della Misericordia, Udine, Italy

Background: Primary Sjögren's syndrome (pSS) is a chronic slowly progressive 